\title{
Measurement bias between optical coherence tomography instruments can affect access to treatment: a new lottery
}

This article was published in the following Dove Press journal:

Clinical Ophthalmology

II December 2013

Number of times this article has been viewed

\author{
Andrej Kidess \\ Adonis El Salloukh \\ Poonam Dutt \\ Pearse A Keane \\ Marie D Tsaloumas \\ Alastair K Denniston \\ Queen Elizabeth Hospital \\ Birmingham, University \\ Hospitals Birmingham NHS \\ Foundation Trust, Birmingham, UK
}

Correspondence: Alastair K Denniston Queen Elizabeth Hospital Birmingham, University Hospitals Birmingham NHS Foundation Trust, Mindelsohn Way, Edgbaston, Birmingham, BI5 2WB, UK Email a.denniston@bham.ac.uk

\section{Dear editor}

It is with great interest that we read the publication entitled "Critical appraisal of ranibizumab in the treatment of diabetic macular edema" by Stewart. ${ }^{1}$ The author emphasized the importance of the vascular endothelial growth factor (VEGF) in the pathophysiology of diabetic macular edema (DME). As highlighted in that article, the anti-VEGF ranibizumab is a superior treatment compared to traditional argon photocoagulation, leading to better anatomical and functional results.

In April 2013, the National Institute for Health and Care Excellence (NICE) of the UK approved the use of ranibizumab as a treatment option to treat diabetic macular edema of the eye if it has a central macular thickness (CMT) of $400 \mu \mathrm{m}$ or more at the beginning of the treatment. ${ }^{2}$ The guidelines did not specify which optical coherence tomography (OCT) device(s) should be used for this assessment. This is important as, although good consistency has been shown in using the same instrument, there is a known divergence in CMT measurements between different instruments. ${ }^{3-6}$ For example, the Spectralis ${ }^{\circledR}$ OCT (Heidelberg Engineering; Carsbad, CA, USA) generally shows higher values of mean CMT in a normal eye compared to most other instruments, in part due to the retinal segmentation algorithm that it employs. ${ }^{4}$ We hypothesized that similar (or increased) differences might be observed in DME, and that for those countries (such as the UK) where a fixed CMT is used to define eligibility for treatment, the "lottery" of OCT instruments may influence eligibility.

In light of this hypothesis, we conducted a preliminary analysis of 24 patients (48 eyes) with suspected DME who had OCT scans performed on the same day using both 3D OCT-1000 (Topcon; Itabashi, Tokyo, Japan) and Spectralis OCT. Matched macular-centered scans were obtained in 42 eyes; scans were not possible in 6 eyes due to media opacity or problems with patient fixation. The mean (standard deviation) CMT in this cohort was $282.0(89.0) \mu \mathrm{m}$ with a range of 191-689 $\mu \mathrm{m}$ using the Topcon OCT, and $312.4(88.8) \mu \mathrm{m}$ with a range of $224-719 \mu \mathrm{m}$ using the Spectralis OCT (Figure 1A). Comparing the two instruments in our cohort using a Bland-Altman analysis, there was a bias of $+10.73 \mu \mathrm{m}$ to the Spectralis with a standard deviation of 10.32 , and $95 \%$ limits of agreement of -9.497 to $30.96 \mu \mathrm{m}$ (Figure 1B).

Recognizing this issue is important for all those involved in care of patients in countries or institutions where the entry to treatment is limited by a defined CMT level. In the specific example considered here, this finding has a direct clinical impact on patients who have DME with a central macular thickness of 390-410 $\mu \mathrm{m}$. In our small 

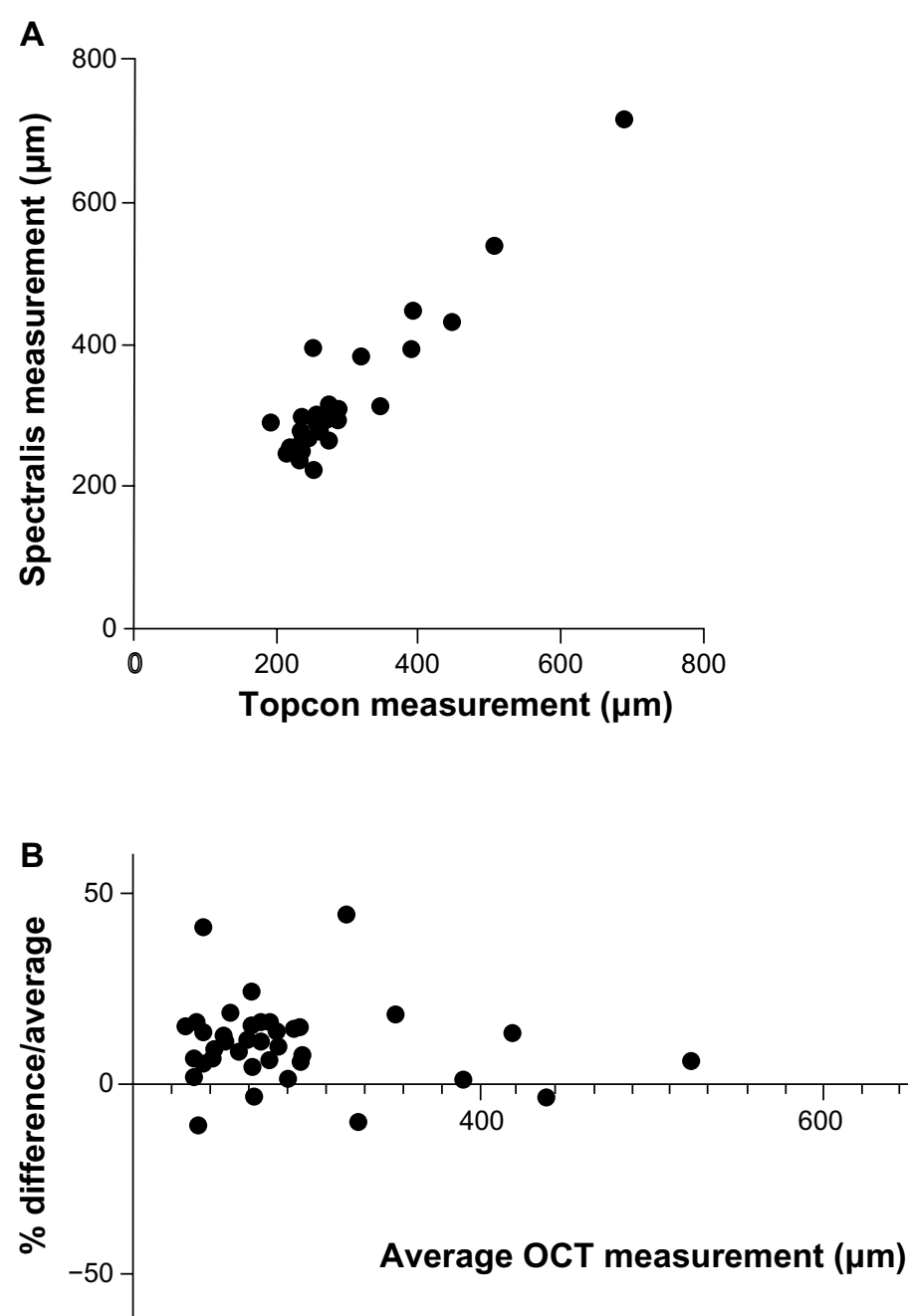

Figure I Comparison of CMT measurements acquired on Topcon 3D OCT-I000 versus Spectralis ${ }^{\circledR}$ OCT for patients with DME. Direct comparison (A) and BlandAltman plot (B).

Notes: Spectralis ${ }^{\circledast}$ OCT manufactured by Heidelberg Engineering (Carsbad, CA, USA); 3D OCT-I000 manufactured by Topcon (Itabashi, Tokyo, Japan).

Abbreviations: CMT, central macular thickness; DME, diabetic macular edema; OCT, optical coherence tomography.

cohort of matched scans from 42 eyes, there were three whose CMT was $>400 \mu \mathrm{m}$ on the Topcon and four whose CMT was $>400 \mu \mathrm{m}$ on the Spectralis: ie, even in this small study, a patient's eligibility for treatment depended on which scan was used. "Real-world" studies of OCT will become increasingly important if defined CMT levels are to be used as the "gate-keeper" for treatment, and should include repeatability and inter-instrument variability in defined patient cohorts.

\section{Disclosure}

Dr Keane is funded by the Department of Health's NIHR Biomedical Research Centre for Ophthalmology at Moorfields Eye Hospital and UCL Institute of Ophthalmology. The views expressed in the publication are those of the author and not necessarily those of the Department of Health. None of the authors have any other conflicts of interest to declare.

\section{References}

1. Stewart MW. Critical appraisal of ranibizumab in the treatment of diabetic macular edema. Clin Ophthalmol. 2013;7:1257-1267.

2. Ranibizumab for treating diabetic macular oedema (rapid review of technology appraisal guidance 237) [webpage on the Internet]. London: National Institute for Health and Clinical Excellence; 2013. Available from: http://publications.nice.org.uk/ranibizumab-for-treating-diabeticmacular-oedema-rapid-review-of-technology-appraisal-guidance-ta274. Accessed August 31, 2013.

3. Grover S, Murthy RK, Brar VS, Chalam KV. Comparison of retinal thickness in normal eyes using Stratus and Spectralis optical coherence tomography. Invest Ophthalmol Vis Sci. 2010;51(5):2644-2647.

4. Wolf-Schnurrbusch UE, Ceklic L, Brinkmann CK, et al. Macular thickness measurements in healthy eyes using six different optical coherence tomography instruments. Invest Ophthalmol Vis Sci. 2009;50(7):3432-3437.

5. Leung CK, Cheung CY, Weinreb RN, et al. Comparison of macular thickness measurements between time domain and spectral domain optical coherence tomography. Invest Ophthalmol Vis Sci. 2008;49(11):4893-4897.

6. Bentaleb-Machkour Z, Jouffroy E, Rabilloud M, Grange JD, Kodjikian L. Comparison of central macular thickness measured by three OCT models and study of interoperator variability. ScientificWorldJournal. 2012;2012:842795. 


\section{Author's reply}

\section{Michael W Stewart \\ Department of Ophthalmology, Mayo Clinic School of Medicine, Jacksonville, FL, USA}

Correspondence: Michael W Stewart

Department of Ophthalmology,

Mayo Clinic School of Medicine,

4500 San Pablo Rd,

Jacksonville, FL 32224, USA

Email stewart.michael@mayo.edu

\section{Dear editor}

We thank Kidess et al for their insightful comments regarding the use of ranibizumab for the treatment of diabetic macular edema (DME). Ranibizumab received US Food and Drug Administration approval for the treatment of DME based primarily on the results of the parallel Phase III registration trials RISE (A Study of Ranibizumab Injection in Subjects With Clinically Significant Macular Edema With Center Involvement Secondary to Diabetes Mellitus) and RIDE (A Study of Ranibizumab Injection in Subjects With Clinically Significant Macular Edema With Center Involvement Secondary to Diabetes Mellitus) ${ }^{1}$ and, not surprisingly, reimbursement for this expensive vascular endothelial growth factor (VEGF)-blocking drug is partially based on findings from these trials. For patients with DME, the Centers for Medicare and Medicaid Services (CMS) reimburse for intravitreal ranibizumab regardless of macular thickness, but the National Institute for Health and Care Excellence (NICE) of the UK requires a central macular thickness of at least $400 \mu \mathrm{m}$, without stipulating which optical coherence tomography (OCT) machine is used. ${ }^{2}$ By demonstrating that macular thickness measurements depend upon the spectral domain-OCT (SDOCT) model used, Kidess et al have uncovered a flaw in the treatment guidelines that may arbitrarily restrict access to treatment for patients in the UK and any other country that ties treatment eligibility to macular thickness.

Patients in the RISE and RIDE trials had central macular thickness (CMT) measurements of at least $275 \mu \mathrm{m}$ by timedomain OCT (TD-OCT), ${ }^{1}$ and average CMT of all enrolled patients was $466 \mu \mathrm{m}$ (with an approximate standard deviation of 158). Previously published studies show that SD-OCT machines consistently give CMT measurements that are 36-74 $\mu \mathrm{m}$ greater (depending on the model of SD-OCT) than those from TD-OCT, ${ }^{3-5}$ thereby suggesting that the mean CMT in RISE and RIDE would have ranged from $502 \mu \mathrm{m}$ (Spectral $^{\circledR}$; Opko/OTI, Inc, Miami, FL, USA) to $540 \mu \mathrm{m}$ (Spectralis ${ }^{\circledR}$; Heidelberg Engineering, Carsbad, CA, USA) if measured with SD-OCT machines. For eyes with CMT near $400 \mu \mathrm{m}$, the choice of SD-OCT model is critical to determining eligibility to receive ranibizumab. For example, a CMT measurement of $418 \mu \mathrm{m}$ with the Spectralis (eligible) would be only $380 \mu \mathrm{m}$ with the Spectral (ineligible). If we assume that the CMTs in the RISE and RIDE trials followed a normal distribution and are representative of UK patients with DME, then $1.75 \%-7.5 \%$ of eyes could not receive ranibizumab simply because the "wrong" SD-OCT model had been selected.

The ranibizumab eligibility limit has created a second concern that might adversely affect even more patients with DME. Patients were eligible for RISE and RIDE if their CMT was at least $275 \mu \mathrm{m}$ by TD-OCT, which would equate to $311-349 \mu \mathrm{m}$ by SD-OCT. Had the RISE and RIDE population been imaged with SD-OCT, according to NICE criteria, $15.8 \%-25.9 \%$ would not have been eligible to receive ranibizumab. If this population of DME patients was imaged with TD-OCT machines, which are still fully functional in many physicians' offices, the size of the ineligible cohort increases to $33.8 \%$.

What are the consequences of not administering ranibizumab to patients whose macular thicknesses measure less than $400 \mu \mathrm{m}$ ? In this setting, treatment options include observation, laser photocoagulation, intraocular corticosteroids, or bevacizumab. Level II evidence suggests that the off-label use of intravitreal bevacizumab effectively resolves edema and improves visual acuity, ${ }^{6}$ but level I evidence will not be available until completion of the Diabetic Retinopathy Clinical Research Network (DRCR.net) protocol T. ${ }^{7}$ Laser photocoagulation and triamcinolone do not dramatically improve vision, ${ }^{8}$ and delaying the institution of effective anti-VEGF therapy results in months to years of "lost" vision, but the long term consequences have not been determined. ${ }^{9}$

Although we believe that a group of patients with DME will be undertreated because of the $400 \mu \mathrm{m}$ exclusion limit, the theoretical calculations in this letter have not been tested in clinical trials. We commend Kidess et al for drawing attention to treatment eligibility based upon imaging parameters and encourage them to continue their "real life" studies to help us better understand the consequences of exclusionary policies.

\section{Disclosure}

Michael W Stewart is on the advisory boards for Allergan and Regeneron, and is a consultant to BoehringerIngelheim. 


\section{References}

1. Nguyen QD, Brown DM, Marcus DM, et al; RISE and RIDE Research Group. Ranibizumab for diabetic macular edema: results from 2 phase III randomized trials: RISE and RIDE. Ophthalmology. 2012; 119(4):789-801.

2. Ranibizumab for treating diabetic macular oedema (rapid review of technology appraisal guidance 237) [webpage on the Internet]. London: National Institute for Health and Clinical Excellence; 2013. Available from: http://publications.nice.org.uk/ranibizumab-for-treating-diabeticmacular-oedema-rapid-review-of-technology-appraisal-guidance-ta274. Accessed October 10, 2013.

3. Grover S, Murthy RK, Brar VS, Chalam KV. Comparison of retinal thickness in normal eyes using Stratus and Spectralis optical coherence tomography. Invest Ophthalmol Vis Sci. 2010;51(5):2644-2647.

4. Wolf-Schnurrbusch UE, Ceklic L, Brinkmann CK, et al. Macular thickness measurements in healthy eyes using six different optical coherence tomography instruments. Invest Ophthalmol Vis Sci. 2009;50(7): 3432-3437.

5. Leung CK, Cheung CY, Weinreb RN, et al. Comparison of macular thickness measurements between time domain and spectral domain optical coherence tomography. Invest Ophthalmol Vis Sci. 2008;49(11): 4893-4897.
6. Diabetic Retinopathy Clinical Research Network, Scott IU, Edwards AR, et al. A phase II randomized clinical trial of intravitreal bevacizumab for diabetic macular edema. Ophthalmology. 2007;114:1860-1867.

7. Diabetic Retinopathy Clinical Research Network. Comparative Effectiveness Study of Intravitreal Aflibercept, Bevacizumab, and Ranibizumab for DME (Protocol T). Available from: http://clinicaltrials.gov/show/NCT01627249. NLM identifier: NCT01627249. Accessed October 15, 2013.

8. Elman MJ, Bressler NM, Qin H, et al; Diabetic Retinopathy Clinical Research Network. Expanded 2-year follow-up of ranibizumab plus prompt or deferred laser or triamcinolone plus prompt laser for diabetic macular edema. Ophthalmology. 2011;118:609-614.

9. Do DV, Nguyen QD, Khwaja AA, et al; READ-2 Study Group. Ranibizumab for edema of the macula in diabetes study: 3-year outcomes and the need for prolonged frequent treatment. JAMA Ophthalmol. 2013;131(2):139-145.

\section{Clinical Ophthalmology}

\section{Publish your work in this journal}

Clinical Ophthalmology is an international, peer-reviewed journal covering all subspecialties within ophthalmology. Key topics include: Optometry; Visual science; Pharmacology and drug therapy in eye diseases; Basic Sciences; Primary and Secondary eye care; Patient Safety and Quality of Care Improvements. This journal is indexed on Submit your manuscript here: http://www.dovepress.com/clinical-ophthalmology-journal

\section{Dovepress}

PubMed Central and CAS, and is the official journal of The Society of Clinical Ophthalmology (SCO). The manuscript management system is completely online and includes a very quick and fair peer-review system, which is all easy to use. Visit http://www.dovepress.com/ testimonials.php to read real quotes from published authors. 